\title{
SELECTION OF NON-COMPETIVE LEPTIN ANTAGONISTS USING A RANDOM NANOBODY-BASED APPROACH
}

Short title: leptin receptor specific nanobodies

Lennart Zabeau ${ }^{1}$, Annick Verhee ${ }^{1}$, Dominiek Catteeuw ${ }^{1}$, Liesbeth Faes ${ }^{1}$, Sylvie Seeuws $^{2}$, Tine Decruy ${ }^{2}$, Dirk Elewaut ${ }^{2}$, Frank Peelman ${ }^{1}$, and Jan Tavernier ${ }^{1,}$

1: Flanders Institute for Biotechnology, Department of Medical Protein Research, Ghent University, Faculty of Medicine and Health Sciences, A. Baertsoenkaai 3, 9000 Ghent, Belgium

2: Laboratory for Molecular Immunology and Inflammation, Department of Rheumatology, Ghent University Hospital, Ghent University, De Pintelaan 185, 9000 Ghent, Belgium

Address correspondance to: Jan Tavernier, A. Baertsoenkaai 3, B-9000 Ghent, Belgium Tel: +32-9-2649302; fax: +32-9-2649492; E-mail: jan.tavernier@vibugent.be 


\section{SYNOPSIS}

The adipocyte-derived cytokine leptin acts as a metabolic switch, connecting the body's metabolism to high energy consuming processes such as reproduction and immune responses. Accumulating evidence suggests that leptin plays a role in human pathologies like autoimmune diseases and cancer, thus providing a rationale for the development of leptin antagonists. In this study, we generated and evaluated a panel of neutralizing nanobodies targeting the leptin receptor (LR). A nanobody comprises the variable domain of the naturally occurring single-chain antibodies found in members of the Camelidae family. We identified three classes of neutralizing nanobodies targeting different LR subdomains: i.e. the $\mathrm{CRH} 2$, Ig-like and FNIII domains. Only nanobodies directed against the $\mathrm{CRH} 2$ domain inhibited leptin binding. We could show that a nanobody that targets the lg-like domain potently interfered with leptin-dependent regulation of hypothalamic neuropeptide $Y$ expression. As a consequence, daily intraperitoneal injection increased body weight, body fat content, food intake, liver size and serum insulin levels. All these characteristics resemble the phenotype of leptin and LR deficient animals. Our data support proposed models of the activated LR complex, and demonstrate that it is possible to block LR signalling without affecting ligand binding. These nanobodies form new tools to study the mechanisms of blood-brain-barrier leptin transport and the effect of LR inhibition in disease models.

Key words: leptin receptor, signalling, receptor activation, nanobodies, body weight

Abbreviations used: ARC: arcuate nucleus, BBB, blood-brain-barrier, $\mathbf{C R H}$, cytokine receptor homology; EC, extracellular domain; FNIII, fibronectin type III; IL, interleukin; JAK, Janus kinase; LIF, leukaemia inhibitory factor; LR, leptin receptor; NPY, neuropeptide Y; PEG, polyethylene glycol; PGK1, phosphoglycerate kinase 1; rPAP1, rat pancreatitis associated protein 1; SEAP, secreted alkaline phosphatase; STAT, signal transducer and activator of transcription. 


\section{INTRODUCTION}

The crucial role of leptin in the long-term control of body weight is well established. This cytokine with hormone-like characteristics is mainly produced and secreted by adipocytes, and plasma protein levels positively correlate with body fat energy stores $[1,2]$. Spontaneous loss-of-function mutations in the leptin-encoding ob gene give rise to a complex syndrome that includes morbid obesity, hypothermia, infertility, hyperglycemia, decreased insulin sensitivity, and hyperlipidemia [3]. Furthermore, low levels (as evoked by starvation) or the absence of functional leptin (ob/ob mice) appear to correlate with severe immune dysfunctions and an increased risk of infections $[4,5]$. In line with this, leptin appears to play a role in both innate and adaptive immunity (reviewed in [6]).

Leptin mediates its effects upon binding and activation of the leptin receptor (LR). This receptor, encoded by the $d b$ gene [7], is a member of the class I cytokine receptor family. As a result of alternative splicing, six LR isoforms have been characterized (LRa-f): a long form (LRb or LRlo), four short forms (LRa,c,d,f), and a soluble form (LRe). In humans, ectodomain shedding generates a soluble LR variant [8]. All isoforms have an identical extracellular domain consisting of two socalled cytokine receptor homology $(\mathrm{CRH})$ domains, $\mathrm{CRH} 1$ and $\mathrm{CRH} 2$, an immunoglobulin-like (Ig-like) domain in between, and two membrane-proximal fibronectin type III (FNIII) domains (see Figure 2A).

High LRlo expression is observed in certain nuclei of the hypothalamus [9] that are involved in the regulation of body weight. Neuropeptide Y (NPY) neurons are a wellcharacterized target of leptin in this part of the brain [10]. Intracerebroventricular leptin administration results in a decrease in orexigenic NPY mRNA levels $[11,12]$. In order to exert its effects, the blood-borne leptin needs to be transported over the blood-brain-barrier (BBB). It is believed that LRa or LRsh, a short LR variant, mediates the transport of leptin across the BBB: (i) this receptor is highly expressed in brain microvessels [13], transfection in Madin-Darby canine kidney cells allows directed transport of labelled leptin [14], and (iii) rats lacking short LRsh show a marked decrease in the transport [15].

Functional LR expression was also observed in several other cell types including liver, pancreas, lung, kidney, adipose tissues, endothelial cells, and cells of the immune system, thereby forming the basis of the peripheral functions of leptin. Given its role in pathologies like autoimmune diseases and cancer, several leptin and LR antagonists were developed and evaluated. In multiple sclerosis, administration of soluble LR or an anti-LR antibody improved clinical score, slowed disease progression, and reduced disease relapses in the experimental autoimmune encephalomyelitis model [16]. Also, administration of a leptin antagonist in the chronic thioacetamide fibrosis model resulted in a markedly improved survival, and attenuated liver fibrosis [17]. Finally, a leptin peptide receptor antagonist reduces tumour growth, and the expression of pro-angiogenic and pro-proliferative molecules in a mouse model for breast cancer [18].

Like all members of the class I cytokine receptor family, the LR has no intrinsic kinase activity, and uses associated Janus kinase 2 (JAK2) for intracellular signalling. In a generally accepted model, ligand binding leads to activation of JAK2 by cross-phosphorylation. Activated JAK2 then rapidly phosphorylates several tyrosine residues in the cytosolic domain of the receptor, providing binding sites for signalling molecules such as STATs (signal transducers and activators of transcription). JAKs subsequently phosphorylate the STATs, which then translocate as dimers to the nucleus to modulate transcription of target genes. The STAT 
molecule primarily involved in leptin signalling is STAT3 [19].

Members of the Camelidae family (llama, dromedary and camel) produce heavychain antibodies that lack light chains. These Camelid heavy-chain antibodies are composed of a variable domain ( $\mathrm{VH} 1$ ), and two constant domains, $\mathrm{CH} 2$ and $\mathrm{CH} 3$ $[20,21]$. The cloned and isolated variable domain, also called nanobody, is a stable polypeptide harbouring the full antigen-binding capacity of the original heavy-chain antibody. Major advantages over classical antibodies are their tissue penetration, stability, easier genetic manipulation and expression in bacteria. Although this technology is relatively new, selected nanobodies can display therapeutic efficacy in mouse disease models. For example, a nanobody that targets TNF $\alpha$ reduces disease severity in a murine model of collagen-induced arthritis [22].

In this study, we have generated nanobodies against the extracellular part of the mouse LR ( $\left.m L R_{E C}\right)$. We identified three different classes of neutralizing nanobodies and mapped the targeted LR subdomains. At least one of the nanobodies appears to be highly efficient in blocking leptin's metabolic functions in vivo. Findings are discussed in the context of structural requirements for LR activation, and transport over the BBB. 


\section{EXPERIMENTAL}

\section{Cell culture and reagents}

Hek293T and hypothalamic N38 cells [23] were grown in Dulbecco's modified Eagle's medium (Invitrogen) with $4500 \mathrm{mg} / \mathrm{liter}$ glucose supplemented with 10\% fetal bovine serum (Invitrogen) in $10 \% \mathrm{CO}_{2}$ humidified atmosphere at $37^{\circ} \mathrm{C}$.

Recombinant mouse leptin, cloned in the pET11a vector (Novagen), was expressed in E. coli, solubilized in $7 \mathrm{M}$ urea, and refolded. Proteins were purified to homogeneity by anion-exchange chromatography on a HiTrap ANX FF column (GE Healthcare) followed by gelfiltration on a HiLoad Superdex 75 column (GE Healthcare). Leptin concentrations were determined by OD measurement at 280 $\mathrm{nm}$. To prolong the half-life in circulation, leptin was pegylated with a $40 \mathrm{kDa}$ PEG (polyethylene glycol) variant (Sunbright) according to the manufacturer's instructions.

Serum insulin levels were measured with ELISA according to the manufacturer's instructions (BioVendor).

\section{Production and purification of the soluble $m L R$ extracellur ( $m L R_{E C}$ ) domain The sequence encoding the complete extracellular domain of the $\mathrm{mLR}$ was amplified and cloned in the pMET7 expression vector. A C-terminal FLAG tag was added in the PCR amplification. The recombinant protein was expressed in Hek293T cells, and purified from the supernatants using an anti-FLAG affinity resin according to the manufacturer's instructions (Sigma).}

\section{Generation and production of LR domain-SEAP fusion proteins}

In the fusion proteins (cloned in the pMET7 expression vector), different LR subdomains, or a combination thereof, were fused to SEAP. pMET7 CRH1-Ig-CRH2SEAP plasmid was used as a starting vector to generate all others, and was constructed as follows: via site-directed mutagenesis (Stratagene) with oligo's 1 and 2 (see table 1), a unique Bgl II site was introduced just before the sequence coding for the FNIII domains in the pMET7 $\mathrm{mLR}$ plasmid. The SEAP coding sequence was amplified with oligo's 3 and 4 , and cloned in the Bgl II - Xba I opened mutant vector. pMET7 CRH1-Ig-SEAP and pMET7 CRH1-SEAP are generated by introducing a Bgl II site just before the CRH2 (oligo's 5 and 6) or Ig-like (oligo's 7 and 8) coding sequences, respectively. Mutant vectors were Bgl II cut and circularised. pMET7 IgCRH2-SEAP and pMET7 CRH2-SEAP were made by Afl II - Hind III digestion of plasmids pMET7 mLR $\triangle \mathrm{CRH} 1$ and pMET7 $\triangle \mathrm{CRH1}, \Delta \mathrm{lg}$ [24]. Resulting inserts were cloned in the Afl II-Hind III opened pMET7 CRH1-Ig-CRH2-SEAP vector. pMET7 FNIII-SEAP was constructed as described previously [24]. Mutations of residues in the Ig-like domain were described earlier [25]. Resulting plasmids were transfected in Hek293T cells, and supernatants were collected four days later.

\section{Generation of $\mathrm{mLR}$ specific nanobodies}

Procedures for immunisation of llamas, preparation of messenger RNA, construction of the library, and panning were performed as previously described [26, 27]. In brief, llamas were injected with purified $\mathrm{mLR}_{\mathrm{EC}}(100 \mu \mathrm{g}$ on days 0 and 7 , and four additional injections of $50 \mu \mathrm{g}$ ) according to standard immunisation protocols. Blood was collected and lymphocytes isolated. mRNA was prepared and used for cDNA synthesis. Nanobody coding sequences were amplified and cloned in a phage display vector. Three consecutive rounds of phage display and panning $\left(10^{11}\right.$ phages per well of a microtiter plate) were performed on $\mathrm{mLR}_{\mathrm{EC}}$-coated plates (10 
$\mu \mathrm{g} /$ well). A clear enrichment was seen after the second and third round of panning. Colonies were randomly selected and analyzed in a plate-binding assay (see further) for the presence of antigen specific nanobodies in their periplasmic extracts. Nanobody genes of the specific binders were sequenced and subcloned in fusion with a N-terminal myc and six histidine (HIS) tag in the pax51 expression-vector. Overnight expression was induced by the addition of $1 \mathrm{mM}$ IPTG in transformed $E$. coli TG-1 cells. Periplasmic extracts were prepared by osmotic chock, and used as such for further analysis.

\section{Construction, production and purification of bi-specific nanobodies}

Sequences of nanobodies $2.17,4.10$, and 4.11 were genetically fused, via a flexible (Gly) $)_{4}$-Ser-(Gly) ${ }_{3}$-Ser linker, to the sequence of an anti-mouse serum albumin nanobody, mAlb, in the pax51 expression vector. LR selective nanobodies were amplified using the oligo's 9 and 10, mAlb with oligo's 11 and 12. Resulting amplicons were digested with Bam HI - Sfi I, and Bam HI - Bst Ell, respectively, and three-point ligated in the Sfi I - Bst Ell opened pax51 vector.

Proteins were produced and purified by the VIB Protein Service Facility up to $95 \%$ purity.

\section{Neutralisation of leptin-dependent STAT3 signalling in Hek293T transfected cells}

Hek293T cells were transiently co-transfected overnight with the pMET7 mLR expression vector and the STAT3 responsive pXP2d2-rPAP1-luciferase reporter [28] with standard calcium phosphate precipitation. Two days after transfection, cells were resuspended with cell dissociation agent (Invitrogen), seeded in a 96-well plate (Costar) and stimulated overnight with sub-optimal leptin concentrations, or LIF (Chemicon International) and a serial dilution of periplasmic extracts or purified nanobodies. Lysates were prepared (lysis buffer: $25 \mathrm{mM}$ Tris, pH 7.8, 2 mM EDTA, $2 \mathrm{mM}$ dithiothreitol, $10 \%$ glycerol, $1 \%$ Triton $\mathrm{X}-100)$, and $35 \mu \mathrm{l}$ of luciferase substrate buffer $\left(20 \mathrm{mM}\right.$ Tricine, $1.07 \mathrm{mM}\left(\mathrm{MgCO}_{3}\right)_{4} \mathrm{Mg}(\mathrm{OH})_{2} \cdot 5 \mathrm{H}_{2} \mathrm{O}, 2.67 \mathrm{mM}$ $\mathrm{MgSO}_{4} \cdot 7 \mathrm{H}_{2} \mathrm{O}, 0.1 \mathrm{mM}$ EDTA, $33.3 \mathrm{mM}$ dithiothreitol, $270 \mu \mathrm{M}$ coenzyme A, $470 \mu \mathrm{M}$ luciferin, $530 \mu \mathrm{M}$ ATP, final $\mathrm{pH} 7.8$ ) was added per $50 \mu$ l of lysate. Light emission was measured for 5 seconds in a TopCount chemiluminescence counter (Packard).

\section{Inhibition of leptin binding}

Leptin binding was measured using a mouse leptin-SEAP chimeric protein. Therefore, mLR transfected Hek293T cells were washed (wash buffer: Dulbecco's modified Eagle's medium, 0.1\% $\mathrm{NaN}_{3}, 20 \mathrm{mM}$ Hepes, $\mathrm{pH} 7.0,0.01 \%$ Tween 20) and incubated for 90 min at room temperature with a 1/50 dilution of a COS-1 conditioned medium containing the leptin-SEAP chimera (final concentration, \pm 10 $\mathrm{ng} / \mathrm{ml}$ ). Nanobodies (in periplasmic extracts or as purified proteins) or unlabelled leptin were added as indicated. After 3 washing steps, cells were lysed (lysis buffer: $1 \%$ Triton $\mathrm{X}-100,10 \mathrm{mM}$ Tris- $\mathrm{HCl} \mathrm{pH} 7.4)$. Endogenous phosphatases in the lysates were inactivated $\left(65^{\circ} \mathrm{C}, 30 \mathrm{~min}\right)$, and bound secreted alkaline phosphatase activity was measured using the chemiluminescent CSPD substrate (PhosphaLight, Tropix) in a TopCount chemiluminescence counter.

\section{Western blotting}

STAT3 and JAK2 phosphorylation were analyzed as described previously [29]. In brief: mLR transfected Hek293T cells were serum-starved for $5 \mathrm{~h}$, and left untreated 
or stimulated with $100 \mathrm{ng} / \mathrm{ml}$ leptin for $15 \mathrm{~min}$. Lysates were prepared in laemmli loading buffer and proteins blotted overnight. STAT3 phosphorylation was checked using the phospho-STAT3-Tyr705 antibody (Cell Signaling), according to the manufacturer's guidelines. STAT3 expression levels were verified using an antiSTAT3 antibody (Transduction Laboratories, Inc., Lexington, KY). JAK2 expression and phosphorylation in cells transfected with $0.01 \mu \mathrm{g}$ pRK5-JAK2 was revealed using an antiphospho-JAK2 (Y1007, Y1008) antibody (Upstate Biotechnology, Inc., Lake Placid, NY), or an anti-JAK2 antibody (Upstate Biotechnology, Inc.).

Expression of FLAG-tagged LR fusion-proteins was measured using an anti-FLAG antibody (Sigma) using standard Western blot procedures.

\section{Plate-binding assays}

Domain mapping: Domains that are bound by specific nanobodies were mapped in a plate-binding assay: Maxisorp (Costar) plates were coated overnight with 0,5 $\mu \mathrm{g} / \mathrm{ml}$ anti-penta HIS Ab (Qiagen) in coating buffer (50 $\mathrm{mM} \mathrm{NaCO}_{3}$; pH 10,6). After three successive washes with PBS $+0,05 \%$ Tween-20 (PBS-T), and blocking with PBS $+0,1 \%$ Casein, nanobodies (as periplasmic extracts or as purified proteins) were allowed to bind for 2 hours. Plates were further washed and incubated for 2 hours with conditioned medium containing the $\mathrm{mLR}$-SEAP fusion proteins. After final washing, bound alkaline phosphatase activity was measured as described above.

Affinity measurements: Affinities of the different nanobodies for the $\mathrm{mLR}$ were determined in a similar plate-binding assay: Maxisorp plates were coated overnight with $2 \mu \mathrm{g} / \mathrm{ml}$ purified nanobody in coating buffer. After washing and blocking, a serial dilution of purified $\mathrm{mLR}_{\mathrm{EC}} \mathrm{SEAP}$ was aliowed to bind for 2 hours. Finally, GraphPad Prism software was used to calculate the affinities from the bound alkaline phosphatase measurments.

Quantification nanobodies in serum: Anti-penta HIS coated plates were incubated with a serial dilution purified nanobody as a standard, or a 1:1000 dilution mouse serum for two hours, and subsequent allowed to bind $m L R_{E C}-S E A P$. Serum concentrations were calculated from the standard curves using the GraphPad Prism software.

\section{Animal experiments}

C57BL/6 mice were purchased from Harlan Netherlands and used in agreement with the institutional guidelines. 9 to 10 week old animals were treated as described and weighed on a daily basis. In some experiments, mice were sacrificed by cervical dislocation and different organs dissected.

\section{Quantitative RT-PCR}

N38 cells: Cells grown in 6-well plates were serum-starved overnight. After 2 hours pre-incubation with different concentrations 4.10-mAlb, cells were stimulated with $500 \mathrm{ng} / \mathrm{ml}$ leptin or were left unstimulated for 4 hours. Hypothalami: Mice were treated daily with 4.10-mAlb (100 $\mu \mathrm{g} / \mathrm{mouse} /$ day) for one week. Pegylated leptin (50 $\mu \mathrm{g} /$ mouse/day) was injected intraperitoneally on day 8 and 9 , and mice were sacrificed by cervical dislocation on day 10 and hypothalami dissected.

Cells and hypothalami were lysed and RNA was prepared using the RNeasy protocol according to the manufacturer's instructions (Qiagen). $500 \mathrm{ng}$ total RNA was used to prepare cDNA with the PrimeScript ${ }^{T M}$ RTase (TaKaRa Bio). A 1/10 dilution of the cDNA was amplified in quantitative PCR following the LightCycler 
480 SYBR Green I Master (Roche Applied Science) guidelines. In brief, a $15 \mu \mathrm{l}$ reaction system containing CDNA, Mastermix, probe solution and specific primer pairs was processed in a LightCycler 480 Real-Time PCR System thermocycler (Roche Applied Science), and the results were analyzed as previously described [30]. Primers for PGK1 (oligo's 13 and 14) and NPY (oligo's 15 and 16) are listed in table 1. All reactions were run in triplicate. The fold change of NPY mRNA expression was calculated by normalizing the absolute amount to the internal control PGK1.

\section{Statistical Analysis}

For analyses of unrelated two-group, Mann-Whitney $U$ tests were performed using the SPSS software. $P$ values $<0.05$ were considered statistically significant. 


\section{RESULTS}

\section{Generation of nanobodies that selectively block leptin signalling.}

In this study, we have generated and evaluated a panel of mLR-specific nanobodies. Llamas were immunized with purified extracellular mLR domain $\left(m L R_{E C}\right)$, the nanobody repertoire was sub-cloned in a phage display vector and panned in three panning-rounds. Panning procedures essentially differed in the strength and length of the washing steps. Nanobodies were prepared by osmotic shock and a plate-binding assay was used to select mLR-specific nanobodies (data not shown). The effect of these nanobodies on leptin signalling was evaluated on Hek293T cells transiently co-transfected with the mLR and the STAT3 responsive pXP2d2-rPAP1-luciferase reporter. Cells were stimulated overnight with sub-optimal leptin concentrations (here $20 \mathrm{ng} / \mathrm{ml}$ ) in the presence of serial dilutions of periplasmic extract containing the different nanobodies. A typical example is given in figure 1A. Fifty-one out of a total of hundred forty four tested nanobodies were able to block STAT3-dependent LR signalling. To test the specificity of this inhibition, we also stimulated the transfected cells with leukemia inhibitory factor (LIF) in combination with the nanobodies. The LIF receptor is endogenously expressed in Hek293T cells and also activates the rPAP1-luciferase reporter in a STAT3 dependent manner. As illustrated in panel b (Figure 1), none of the nanobodies had an effect on LIF signalling. The neutralizing nanobodies were selected for further experiments.

A subset of neutralizing nanobodies inhibits binding of leptin to its receptor. To evaluate the effect on ligand binding, mLR transfected Hek293T cells were incubated with a leptin-SEAP (secreted alkaline phosphatase) chimeric protein, in combination with nanobodies or unlabelled leptin as a positive control. After two hours, cells were washed and the bound alkaline phosphatase activity was measured (Figure 1C). Two of the fifty-one neutralising nanobodies tested interfered with leptin binding, readily explaining their neutralizing effect.

Neutralizing nanobodies bind to the CRH2, Ig-like or FNIII domains. Chimeric proteins consisting of individual $\mathrm{mLR}$ subdomains, or a combination thereof, coupled to SEAP were used to determine the specificity of the different neutralizing nanobodies. A schematic presentation of the LR extracellular architecture is shown in figure $2 A$. Soluble recombinant $\mathrm{mLR}$ domain-SEAP chimeric proteins were expressed in Hek293T cells and used in a plate-binding assay. Plates coated with anti-penta-HIS antibody were used to capture the HIStagged nanobodies from periplasmic extracts and were subsequently incubated with the different mLR-SEAP fusion proteins. After several washing steps, bound enzymatic activity was measured. Typical results for an Ig-like binder (interacts with CRH1-lg-SEAP and lg-CRH2-SEAP), a CRH2 binder (interacts with lg-CRH2-SEAP and CRH2-SEAP), and a FNIII binder (only interaction with FNIII-SEAP) are shown in panels b, c, and $d$ (Figure 2 ) respectively. These data demonstrate that targeting the $\mathrm{CRH} 2$, ig or FNIII domains in the mLR can result in neutralisation of receptor activation. The nanobodies that interfered with ligand binding were found to target the $\mathrm{CRH} 2$ domain, in line with this domain being the main leptin-binding determinant. In parallel experiments, we were able to identify and characterize $\mathrm{CRH} 1$ specific nanobodies. None of these were able to block leptin binding or signalling (data not shown). 


\section{Ig-like specific nanobodies support the role of residues H417 and H418 in LR activation.}

To understand the neutralising properties of the Ig-like specific nanobodies, we performed a similar plate-binding assay with mutated LR variants. Ig-like residues involved in receptor activation, Y409, H417, and H418, were mutated in the $\mathrm{CLR}_{\mathrm{EC}}-$ SEAP construct, and proteins expressed in Hek293T cells. None of the mutations had a drastic effect on expression and secretion as illustrated by anti-FLAG Western blot analysis (Figure 3A) or measurement of alkaline phosphatase activity in the supernatants (Figure 3B). Ig-like specific nanobodies were bound to antipenta-His coated plates, incubated with wild type or mutant $\mathrm{mLR}_{\mathrm{EC}}$, and bound phosphatase activity measured and plotted as \% of wild type binding (Figure 3C). Mutation of $\mathrm{H} 417$ and to a lesser extent $\mathrm{H} 418$ disrupts binding of the neutralising nanobodies 4.14 and 4.18, suggesting that these two residues are part of their epitope.

Bispecific nanobodies inhibit leptin signalling in a dose-dependent manner. Based on these experiments, we have selected three neutralising nanobodies: 2.17 (against $\mathrm{CRH} 2$, interferes with leptin binding), 4.10 (against Ig-like), and 4.11 (against FNIII). In the light of future in vivo experiments, we converted these into a bispecific format. Using a flexible Gly-Ser linker they were fused to the mAlb nanobody that targets mouse serum albumin (Figure 4A). One advantage is that binding to endogenous serum albumin greatly prolongs half-life of the resulting bispecific nanobodies in circulation in vivo. Recombinant proteins (2.17-mAlb, 4.10$\mathrm{mAlb}$, and 4.11-mAlb) were purified to homogeneity. These bispecific nanobodies retained their mouse albumin-binding capacities (data not shown). We re-tested their effect on STAT3 dependent LR signalling in transfected Hek293T cells (see also above). Data in figure 4B illustrate that 4.10 is significantly more effective in neutralisation when compared to 2.17-mAlb and 4.11-mAlb. Two crucial steps in LR signalling, i.e. initial JAK2 phosphorylation and subsequent STAT3 phosphorylation, were studied in more detail using Western blot analysis. Data in panel c illustrate that all three nanobodies interfered with JAK2 phosphorylation, and STAT3 activation. Differences in inhibition capacity are similar to these observed in the reporter-assay.

Binding characteristics of the bispecific nanobodies.

We re-tested the bispecific nanobodies in a leptin-binding assay using the leptinSEAP fusion protein (see also above). Hek293T transfected cells were incubated with supernatants containing the leptin-SEAP chimera, in the presence of purified bispecific nanobodies or unlabelled leptin as positive control (concentrations as indicated). After four successive washes, bound alkaline phosphatase activity was measured (Figure 5A). While 2.17-mAlb clearly blocks ligand binding, no effect of the two other bispecific nanobodies was observed.

Affinities of 2.17-mAlb, 4.10-mAlb, and 4.11-mAlb for the mLR were determined in a plate-binding assay. Maxisorp plates were coated with different nanobodies, blocked, and allowed to bind a serial dilution of $\mathrm{mLR}_{\mathrm{EC}}-\mathrm{SEAP}$ (as indicated). Bound alkaline phosphatase activity was plotted in function of $m L R_{E C}-S E A P$ concentrations in figure 5B. Affinities calculated with the GraphPad Prism software were comparable for the three bispecific nanobodies and in the lower nM range. 


\section{Daily administration of $\mathrm{mLR}$-specific nanobodies in mice can result in weight gain}

Given the fact that leptin plays a crucial role in the regulation of body weight, we tested the three nanobodies in vivo. Therefore, $2.17-\mathrm{mAlb}(100 \mu \mathrm{g} / \mathrm{mouse} /$ day $)$, 4.10-mAlb (100, 40, and $10 \mu \mathrm{g} / \mathrm{mouse} / \mathrm{day})$, or 4.11-mAlb (100 $\mu \mathrm{g} / \mathrm{mouse} / \mathrm{day})$ was administered on a daily basis in 9 to 10 week old C57BL/6 mice for 7 days. PBS served as a negative control in this experiment. Data in figure 6A clearly illustrate that 4.10-mAlb $(100 \mu \mathrm{g})$ provokes a significant increase in body weight. Injections of $40 \mu \mathrm{g}$ 4.10-mAlb or $100 \mu \mathrm{g} 2.17$ have intermediate effects, while no weight variations could be observed in 4.11-mAlb treated animals.

Besides neutralising capacities (as illustrated on transfected Hek cells; Figure 4B), the effects on body weight can also be explained by differences in stability of the nanobodies in circulation, and thus accumulation, of treated mice. We therefore measured serum concentrations of the nanobodies after a one-week treatment (Figure 6B). 4.10-mAlb $(229 \mu \mathrm{g} / \mathrm{ml})$ levels appear to be significantly higher that 2.17-mAlb (103 $\mu \mathrm{g} / \mathrm{ml})$, or 4.11-mAlb $(52 \mu \mathrm{g} / \mathrm{ml})$.

\section{Nanobody treatment results in hyperphagia, increased fat and liver mass and hyperinsulinemia}

Mice were treated for 14 days with 4.10-mAlb (100 $\mu \mathrm{g} / \mathrm{mouse} / \mathrm{day})$ or PBS. Animals were weighed daily and food-intake was monitored. Data summarized in table 2 clearly show that daily nanobody administration induced hyperphagia (food consumption of $71,07 \mathrm{~g} \pm 1,48$ vs $52,32 \mathrm{~g} \pm 1,57$ when treated with PBS) and resulted in significant increase in body weight. After two weeks, mice were sacrificed and fat pads and livers were dissected and weighed. Masses of both were significantly increased upon treatment with 4.10-mAlb. Finally, serum insulin concentrations were measured and appeared to be significantly elevated in animals treated with the bi-specific nanobody.

\subsection{0-mAlb blocks leptin mediated regulation of NPY expression both in vitro and in vivo}

Treatment with the bi-specific nanobody clearly resulted in weight gain and increase in food intake, and thus likely affects signalling in the hypothalamus. To test this hypothesis, we examined the effect of 4.10-mAlb on NPY expression by leptin.

We initially used the hypothalamic murine N38 cell line [23]. Serum-starved cells were pre-incubated with indicated concentrations of bi-specific nanobody before stimulating 4 hours with leptin or were left untreated. Cells were lysed and NPY expression was quantified with real-time RT-PCR. Data in figure 7A clearly show that 4.10-mAlb dose-dependently blocked the leptin-mediated down-regulation of NPY expression.

To examine the effects in vivo, mice were treated for one week with 4.10-mAlb or PBS. NPY transcriptional regulation was induced by two injections of pegylated leptin on days 8 and 9. One day later, mice were sacrificed, hypothalami dissected, and RNA was prepared for quantitative RT-PCR analysis. While pegylated leptin administration resulted in a decrease in NPY expression in PBS treated mice, no significant differences (pegylated leptin vs PBS) were observed in animals treated with 4.10-mAlb (Figure 7B). 


\section{DISCUSSION}

To gain more insights in the structural requirements for LR activation, we have generated and evaluated a panel of $\mathrm{mLR}$ specific nanobodies by immunization of llamas with the extracellular part of the receptor. Several nanobodies blocked STAT3 dependent signalling in $\mathrm{mLR}$ transfected Hek293T cells. A plate-binding assay demonstrated that these nanobodies were directed against the $\mathrm{CRH} 2$, Ig like, or FNIII domains in the receptor. We found that only $\mathrm{CRH} 2$ binders were also able to block leptin binding to its receptor. Our data underscore the importance of each of these domains in LR activation.

The $\mathrm{CRH} 2$ domain is the major leptin-binding determinant. Two independent mutagenesis studies, on mouse and chicken receptors, identified a region of four consecutive hydrophobic residues in $\mathrm{CRH} 2$ involved in this interaction [31, 32]. Mutation of these residues affects ligand binding and consequent signailing. The $\mathrm{CRH} 2$ residues (501-IFFL-504 in the mouse receptor) are predicted to make contact with L13 and L86 residues in mouse leptin, both belonging to leptin binding site II [31] (figure 7). The observation that nanobodies directed against this domain are able to interfere with leptin binding confirm the crucial role of $\mathrm{CRH} 2$ in ligand binding.

The Ig-like domain has no detectable binding affinity for leptin, but is nonetheless crucial for LR activation. LR variants lacking this domain show unaltered leptin binding, but are unable to signal via STAT3 [29, 33]. We identified residues L370, A407, Y409, H417, and H418 (located in a large conserved surface patch in the beta-sheet formed by beta-strands 3,6 , and 7) as the centre of the leptin bindingsite in this domain [25]. Mutations herein completely abolished leptin-induced STAT3-dependent reporter activity. In this study, we found that $\mathrm{H} 417$, and to a lesser extent $\mathrm{H418}$, is likely part of the epitope of at least two neutralising nanobodies targeting this Ig-like domain (Figure 3). The location of the corresponding binding-site (also referred to as site III) on leptin remains controversial. Niv-Spector et al. predict site III around residues 39-42 in leptin, while our studies place it around residues $\mathrm{S} 120$ and T121 at the N-terminus of helix D $[25,34]$. Combined mutation of $\mathrm{S} 120$ and T121 or of residues $39-42$ both result in a leptin mutein with antagonistic properties in vitro and in vivo [35]: these muteins bind to $\mathrm{CRH} 2$, but are unable to activate the receptor, thus blocking LR activation. We propose that residues 39-42 may be part of a different binding site, binding site I.

The membrane-proximal FNIII domains also lack any binding affinity for leptin but are indispensible for LR activation [24, 33]. A LR variant with an extracellular domain consisting of only these domains shows a marked increase in ligandindependent signalling [24]. This illustrates that the FNIII domains can position the intracellular domains in such a way that JAK activation and signalling is possible. Combined mutation of two conserved cysteine residues in the FNIII domains (on position 672 and 751 in the mouse receptor) results in a receptor completely devoid of biological activity, but with unaltered leptin-binding characteristics [24]. In line with these data, we here observed that nanobodies targeting the FNIII domains can interfere with LR signalling without affecting leptin binding.

LR activation requires clustering of more than two LR chains. We previously used a complementation of signalling strategy to show that LR activation requires higher order clustering (i.e. more than two receptors)[29]. In the absence of leptin, the receptor can form disulphide-linked dimers, most likely involving $\mathrm{CRH} 2$ cysteine residues, on the cellular membrane $[24,36]$. The existence of these preformed LR 
complexes is supported by BRET experiments [36]. Detailed mutagenesis of leptin identified three potential receptor-binding sites (I, II, and III), in analogy with highly similar IL-6 related cytokines [35]. Based on the hexameric IL-6 receptor complex, we proposed a 2:4 leptin:LR complex where each leptin molecule binds three LR chains via binding sites I, II and III. The hexameric leptin:LR complex is in line with the observed potential for higher order clustering [25]. In these models, the FNIII domains are crucial for translating these spatial reorganisations of the membrane distal domains into spatial reorganisation of the transmembrane and intracellular domains, leading to JAK2 activation.

Insights into the LR activation mechanisms are a prerequisite for the development of new LR antagonists. We here show that nanobodies targeting different domains of the LR interfere with LR activation via different mechanisms: nanobodies against $\mathrm{CRH} 2$ block leptin binding, while nanobodies against the Ig-like domain and FNIII domains block receptor activation without affecting leptin binding. This latter feature is unique when compared to currently used leptin and LR antagonists (leptin mutants, soluble LR variants, leptin peptide antagonists or LPAs, and receptorspecific antibodies [37]).

In this study we could show that targeting the Ig-like domain with 4.10-mAlb blocked leptin-mediated NPY down-regulation both in a hypothalamic cell line and in vivo (figure $8 \mathrm{~A}$ and $\mathrm{B}$ ). Daily administration consequently induced significant increases in food intake, body weight and fat content (summarized in table 2). Livers were also enlarged and serum insulin levels elevated. These characteristics are reminiscent of leptin and LR deficient rodents [38, 39].

The observation that 4.10-mAlb treatment blocks leptin signalling in the hypothalamus is rather unexpected, since it does not interfere with leptin binding and thus possibly not with transport over the BBB by LRsh. There is no evidence from the literature that nanobodies are passively or actively transported across this barrier. The two only nanobodies known to transmigrate in an in vitro human BBB model and in vivo were generated by enrichment of a phage-display nanobody library with human cerebromicrovascular endothelial cells [40]. The in vivo effects of 4.10-mAlb might support the relatively new idea that leptin sensing neurons make direct contact with the blood-circulation. In this context, it becomes clear that neurons of the arcuate nucleus (ARC) behave different from neurons in other sites of the hypothalamus, like the dorso-medial, ventro-medial, and lateral hypothalamus. First, diet-induced-obesity results in a decrease in leptin sensitivity due to over-expression of SOCS3 (a negative regulator of leptin signalling) in ARC neurons, but not in other regions of the brain [41]. Second, it is only possible to detect basal STAT3 phosphorylation in the ARC neurons, and these respond more rapidly and sensitively to exogenous administrated leptin [42]. Third, leptin responsive neurons, which express the LR or show STAT3 activation can be labelled by BBB impermeable fluorescent tracers $[42,43]$.

Taken together, we used a panel of $\mathrm{mLR}$-specific nanobodies to refine the structural requirements for leptin binding and receptor activation. These nanobodies can furthermore help to better understand the mechanisms controlling transport of leptin over the BBB. These insights are essential for the rational design of leptin and LR antagonists for the treatment of autoimmune diseases and cancer. 


\section{ACKNOWLEDGEMENTS}

We are greatly indebted to Jurgen Haustraete and Jannick Leoen from the VIB Protein Service Facility for the production and purification of the nanobodies, Els Beirnaert and Marc Lauwereys from Ablynx for the help with the generation of the nanobody library, and Prof Belsham for the N38 cell line. 


\section{FUNDING}

This work was supported by grants from the Fund for Scientific Research-Flanders [G.0164.O6N] and Ghent University. L.Z. is a postdoctoral fellow of the Fund for Scientific Research-Flanders. S.S. is supported by the Institute for the Promotion of Innovation through Science and Technology in Flanders (IWT-Vlaanderen). 


\section{REFERENCES}

1 Considine, R. V., Sinha, M. K., Heiman, M. L., Kriauciunas, A., Stephens, T. W., Nyce, M. R., Ohannesian, J. P., Marco, C. C., McKee, L. J., Bauer, T. L. and et al. (1996) Serum immunoreactive-leptin concentrations in normal-weight and obese humans. $\mathrm{N}$ Engl J Med. 334, 292-295

2 Maffei, M., Halaas, J., Ravussin, E., Pratley, R. E., Lee, G. H., Zhang, Y., Fei, H., Kim, S., Lallone, R., Ranganathan, S. and et al. (1995) Leptin levels in human and rodent: measurement of plasma leptin and ob RNA in obese and weight-reduced subjects. Nat Med. 1, 1155-1161

3 Montague, C. T., Farooqi, I. S., Whitehead, J. P., Soos, M. A., Rau, H., Wareham, N. J., Sewter, C. P., Digby, J. E., Mohammed, S. N., Hurst, J. A., Cheetham, C. H., Earley, A. R., Barnett, A. H., Prins, J. B. and O'Rahilly, S. (1997) Congenital leptin deficiency is associated with severe early-onset obesity in humans. Nature. 387, 903-908

4 La Cava, A. and Matarese, G. (2004) The weight of leptin in immunity. Nat Rev Immunol. 4, 371-379

5 Matarese, G. (2000) Leptin and the immune system: how hutritional status influences the immune response. Eur Cytokine Netw. 11, 7-14

6 Fernandez-Riejos, P., Najib, S., Santos-Alvarez, J., Martin-Romero, C., PerezPerez, A., Gonzalez-Yanes, C. and Sanchez-Margalet, V. Role of leptin in the activation of immune cells. Mediators Inflamm. 2010, 568343

7 Tartaglia, L. A., Dembski, M., Weng, X., Deng, N., Culpepper, J., Devos, R., Richards, G. J., Campfield, L. A., Clark, F. T., Deeds, J., Muir, C., Sanker, S., Moriarty, A., Moore, K. J., Smutko, J. S., Mays, G. G., Wool, E. A., Monroe, C. A. and Tepper, R. I. (1995) Identification and expression cloning of a leptin receptor, OB-R. Cell. 83, 1263-1271

8 Ge, H., Huang, L., Pourbahrami, T. and Li, C. (2002) Generation of soluble leptin receptor by ectodomain shedding of membrane-spanning receptors in vitro and in vivo. J Biol Chem. 277, 45898-45903

9 Fei, H., Okano, H. J., Li, C., Lee, G. H., Zhao, C., Darnell, R. and Friedman, J. M. (1997) Anatomic localization of alternatively spliced leptin receptors (Ob-R) in mouse brain and other tissues. Proc Natl Acad Sci U S A. 94, 7001-7005

10 Schwartz, M. W., Seeley, R. J., Campfield, L. A., Burn, P. and Baskin, D. G. (1996) Identification of targets of leptin action in rat hypothalamus. J Clin Invest. 98, 1101-1106 11 Stephens, T. W., Basinski, M., Bristow, P. K., Bue-Valleskey, J. M., Burgett, S. G., Craft, L., Hale, J., Hoffmann, J., Hsiung, H. M., Kriauciunas, A. and et al. (1995) The role of neuropeptide $Y$ in the antiobesity action of the obese gene product. Nature. 377, 530-532

12 Ahima, R. S., Prabakaran, D., Mantzoros, C., Qu, D., Lowell, B., Maratos-Flier, E. and Flier, J. S. (1996) Role of leptin in the neuroendocrine response to fasting. Nature. 382, 250-252

13 Bjorbaek, C., Elmquist, J. K., Michl, P., Ahima, R. S., van Bueren, A., McCall, A. L. and Flier, J. S. (1998) Expression of leptin receptor isoforms in rat brain microvessels. Endocrinology. 139, 3485-3491

14 Hileman, S. M., Tornoe, J., Flier, J. S. and Bjorbaek, C. (2000) Transcellular transport of leptin by the short leptin receptor isoform ObRa in Madin-Darby Canine Kidney cells. Endocrinology. 141, 1955-1961

15 Kastin, A. J., Pan, W., Maness, L. M., Koletsky, R. J. and Ernsberger, P. (1999) Decreased transport of leptin across the blood-brain barrier in rats lacking the short form of the leptin receptor. Peptides. 20, 1449-1453

16 De Rosa, V., Procaccini, C., La Cava, A., Chieffi, P., Nicoletti, G. F., Fontana, S., Zappacosta, S. and Matarese, G. (2006) Leptin neutralization interferes with pathogenic T cell autoreactivity in autoimmune encephalomyelitis. J Clin Invest. 116, 447-455

17 Elinav, E., Ali, M., Bruck, R., Brazowski, E., Phillips, A., Shapira, Y., Katz, M., Solomon, G., Halpern, Z. and Gertler, A. (2009) Competitive inhibition of leptin signaling 
results in amelioration of liver fibrosis through modulation of stellate cell function. Hepatology. 49, 278-286

18 Rene Gonzalez, R., Watters, A., Xu, Y., Singh, U. P., Mann, D. R., Rueda, B. R. and Penichet, M. L. (2009) Leptin-signaling inhibition results in efficient anti-tumor activity in estrogen receptor positive or negative breast cancer. Breast Cancer Res. 11, R36

19 Vaisse, C., Halaas, J. L., Horvath, C. M., Darnell, J. E., Jr., Stoffel, M. and Friedman, J. M. (1996) Leptin activation of Stat3 in the hypothalamus of wild-type and ob/ob mice but not db/db mice. Nat Genet. 14, 95-97

20 Hamers-Casterman, C., Atarhouch, T., Muyldermans, S., Robinson, G., Hamers, C., Songa, E. B., Bendahman, N. and Hamers, R. (1993) Naturally occurring antibodies devoid of light chains. Nature. 363, 446-448

21 van der Linden, R., de Geus, B., Stok, W., Bos, W., van Wassenaar, D., Verrips, T. and Frenken, L. (2000) Induction of immune responses and molecular cloning of the heavy chain antibody repertoire of Lama glama. J Immunol Methods. 240, 185-195

22 Coppieters, K., Dreier, T., Silence, K., de Haard, H., Lauwereys, M., Casteels, P., Beirnaert, E., Jonckheere, H., Van de Wiele, C., Staelens, L., Hostens, J., Revets, H., Remaut, E., Elewaut, D. and Rottiers, P. (2006) Formatted anti-tumor necrosis factor alpha $\mathrm{VHH}$ proteins derived from camelids show superior potency and targeting to inflamed joints in a murine model of collagen-induced arthritis. Arthritis Rheum. 54, 1856-1866

23 Belsham, D. D., Cai, F., Cui, H., Smukler, S. R., Salapatek, A. M. and Shkreta, L. (2004) Generation of a phenotypic array of hypothalamic neuronal cell models to study complex neuroendocrine disorders. Endocrinology. 145, 393-400

24 Zabeau, L., Defeau, D., Iserentant, H., Vandekerckhove, J., Peelman, F. and Tavernier, J. (2005) Leptin receptor activation depends on critical cysteine residues in its fibronectin type III subdomains. J Biol Chem. 280, 22632-22640

25 Peelman, F., Iserentant, H., De Smet, A. S., Vandekerckhove, J., Zabeau, L. and Tavernier, J. (2006) Mapping of binding site III in the leptin receptor and modeling of a hexameric leptin.leptin receptor complex. J Biol Chem. 281, 15496-15504

26 Arbabi Ghahroudi, M., Desmyter, A., Wyns, L., Hamers, R. and Muyldermans, S. (1997) Selection and identification of single domain antibody fragments from camel heavychain antibodies. FEBS Lett. 414, 521-526

27 Frenken, L. G., van der Linden, R. H., Hermans, P. W., Bos, J. W., Ruuls, R. C., de Geus, B. and Verrips, C. T. (2000) Isolation of antigen specific llama VHH antibody fragments and their high level secretion by Saccharomyces cerevisiae. J Biotechnol. 78, $11-21$

28 Broekaert, D., Eyckerman, S., Lavens, D., Verhee, A., Waelput, W., Vandekerckhove, J. and Tavernier, J. (2002) Comparison of leptin- and interleukin-6regulated expression of the IPAP gene family: evidence for differential co-regulatory signals. Eur Cytokine Netw. 13, 78-85

29 Zabeau, L., Defeau, D., Van der Heyden, J., Iserentant, H., Vandekerckhove, J. and Tavernier, J. (2004) Functional analysis of leptin receptor activation using a Janus kinase/signal transducer and activator of transcription complementation assay. Mol Endocrinol. 18, 150-161

30 Pfaffl, M. W. (2001) A new mathematical model for relative quantification in real-time RT-PCR. Nucleic Acids Res. 29, e45

31 Iserentant, H., Peelman, F., Defeau, D., Vandekerckhove, J., Zabeau, L. and Tavernier, J. (2005) Mapping of the interface between leptin and the leptin receptor $\mathrm{CRH} 2$ domain. J Cell Sci. 118, 2519-2527

32 Niv-Spector, L., Raver, N., Friedman-Einat, M., Grosclaude, J., Gussakovsky, E. E., Livnah, O. and Gertler, A. (2005) Mapping leptin-interacting sites in recombinant leptinbinding domain (LBD) subcloned from chicken leptin receptor. Biochem. J. 390, 475-484

33 Fong, T. M., Huang, R. R., Tota, M. R., Mao, C., Smith, T., Varnerin, J., Karpitskiy, V. V., Krause, J. E. and Van der Ploeg, L. H. (1998) Localization of leptin binding domain in the leptin receptor. Mol Pharmacol. 53, 234-240 
34 Niv-Spector, L., Gonen-Berger, D., Gourdou, I., Biener, E., Gussakovsky, E. E., Benomar, Y., Ramanujan, K. V., Taouis, M., Herman, B., Callebaut, I., Djiane, J. and Gertler, A. (2005) Identification of the hydrophobic strand in the A-B loop of leptin as major binding site III: implications for large-scale preparation of potent recombinant human and ovine leptin antagonists. Biochem. J. 391, 221-230

35 Peelman, F., Van Beneden, K., Zabeau, L., Iserentant, H., Ulrichts, P., Defeau, D., Verhee, A., Catteeuw, D., Elewaut, D. and Tavernier, J. (2004) Mapping of the leptin binding sites and design of a leptin antagonist. J Biol Chem. 279, 41038-41046

36 Couturier, C. and Jockers, R. (2003) Activation of the leptin receptor by a ligandinduced conformational change of constitutive receptor dimers. J Biol Chem. 278, 2660426611

37 Gertler, A. (2006) Development of leptin antagonists and their potential use in experimental biology and medicine. Trends Endocrinol Metab. 17, 372-378

38 Chen, H., Charlat, O., Tartaglia, L. A., Woolf, E. A., Weng, X., Ellis, S. J., Lakey, N. D., Culpepper, J., Moore, K. J., Breitbart, R. E., Duyk, G. M., Tepper, R. I. and Morgenstern, J. P. (1996) Evidence that the diabetes gene encodes the leptin receptor: identification of a mutation in the leptin receptor gene in $\mathrm{db} / \mathrm{db}$ mice. Cell. 84, 491-495

39 Zhang, Y., Proenca, R., Maffei, M., Barone, M., Leopold, L. and Friedman, J. M. (1994) Positional cloning of the mouse obese gene and its human homologue. Nature. 372, 425-432

40 Muruganandam, A., Tanha, J., Narang, S. and Stanimirovic, D. (2002) Selection of phage-displayed llama single-domain antibodies that transmigrate across human bloodbrain barrier endothelium. FASEB J. 16, 240-242

41 Munzberg, H., Flier, J. S. and Bjorbaek, C. (2004) Region-specific leptin resistance within the hypothalamus of diet-induced obese mice. Endocrinology. 145, 4880-4889

42 Faouzi, M., Leshan, R., Bjornholm, M., Hennessey, T., Jones, J. and Munzberg, H. (2007) Differential accessibility of circulating leptin to individual hypothalamic sites. Endocrinology. 148, 5414-5423

43 Cheunsuang, $O$. and Morris, R. (2005) Astrocytes in the arcuate nucleus and median eminence that take up a fluorescent dye from the circulation express leptin receptors and neuropeptide $Y$ Y1 receptors. Glia. 52, 228-233 


\section{TABLES}

Table 1: List of primers used in this study

\begin{tabular}{|c|c|}
\hline Name & Sequence \\
\hline oligo 1 & 5'-GCTTGTCATGGATGTAAAGATCTCTATGAGAGGGCCTGAATTTTGG-3' \\
\hline oligo 2 & 5'-CCAAAATTCAGGCCCTCTCATAGAGATCTTTACATCCATGACAAGC-3' \\
\hline oligo 3 & 5'-GCGGCGAGATCTCTATCATCCCAGTTGAGGAGGAGAACC-3' \\
\hline oligo 4 & 5'-TCTAGATTAACCCGGGTGCGCGGCGTCGG-3' \\
\hline oligo 5 & 5'-GCTGAATTATACGTGATCGATGTCAAGATCTCTATATCATGTGAAACTGACG-3' \\
\hline oligo 6 & 5'-CGTCAGTTTCACATGATATAGAGATCTTGACATCGATCACGTATAATTCAGC-3' \\
\hline oligo 7 & 5'-CCTCAAGTCTTTACCACACAGATCTTTGTGTATTTTCCACCC-3' \\
\hline oligo 8 & 5'-GGGTGGAAAATACACAAAGATCTGTGTGGTAAAGACTTGAGG-3' \\
\hline oligo 9 & 5'-GGATAACAATTTCACACAGG -3' \\
\hline oligo 10 & 5'-TCAGTAACCTGGATCCGCCACCGCTGCCTCCACCGCCTGAGGAGACGGTGACCTG -3' \\
\hline oligo 11 & 5'-CACGACGTTGTAAAACGAC-3' \\
\hline oligo 12 & 5'-AGGTTACTGAGGATCCGAGGTGCAGCTGGTGGAGTCTGG-3' \\
\hline oligo 13 & 5'-CTCCGCTTTCATGTAGAGGAAG-3' \\
\hline oligo 14 & 5'-GACATCTCCTAGTTTGGACAGTG-3' \\
\hline oligo 15 & 5'-TAGGTAACAAGCGAATGGGG-3' \\
\hline oligo 16 & 5'-ACATGGAAGGGTCTTCAAGC-3' \\
\hline
\end{tabular}


Table 2: Metabolic effects of two week treatment with 4.10-mAlb C57BL/6 mice were treated with 4.10-mAlb $(100 \mu \mathrm{g} /$ day/mouse; $n=6)$ or PBS $(n=$ $6)$ for 14 days. Animals were weighed and food intake was monitored on a daily basis. On day 15, animals were sacrificed, fat pads and livers weighed and serum insulin concentrations measured. Data are expressed as average \pm SEM. ${ }^{*}, \mathrm{P}<0.05$; Mann-Whitney U Test.

\begin{tabular}{l|c|c} 
& PBS & $\mathbf{4 . 1 0}$-mAlb \\
\hline Initial weight $(\mathrm{g})$ & $22,13 \pm 0,67$ & $22,03 \pm 0,54$ \\
Weight after 14 days $(\mathrm{g})$ & $23,45 \pm 0,73$ & $28,20 \pm 0,66$ * \\
Weight gain $(\mathrm{g})$ & $1,32 \pm 0,99$ & $6,17 \pm 0,68$ \\
Cumulative food per mouse (g) & $52,32 \pm 1,57$ & $71,07 \pm 1,48$ * \\
Fat pads (mg) & $308,33 \pm 22,27$ & $668,33 \pm 110,19$ * \\
Liver (mg) & $1195,00 \pm 38,45$ & $1608,33 \pm 63,69$ * \\
Insulin $(\mathrm{ng} / \mathrm{ml})$ & $2,08 \pm 0,45$ & $3,68 \pm 0,45^{*}$
\end{tabular}




\section{FIGURE LEDGENDS}

Figure 1 Effect of nanobodies on STAT3 dependent signalling and leptin binding in transfected Hek293T cells.

(A and B) $\mathrm{mLR}$ and rPAP1-luciferase reporter co-transfected Hek293T cells were stimulated overnight with $20 \mathrm{ng} / \mathrm{ml}$ leptin (A), or $100 \mathrm{ng} / \mathrm{ml}$ LIF (B) in the presence of a serial dilution of nanobody-containing periplasmic extracts (as indicated). Luciferase activity was measured as outlined in the Materials \& Methods section. Data are the mean of triplicate measurements, and results are representative of at least four independent experiments. c mLR expressing Hek293T cells were incubated with leptin-SEAP supernatans, in combination with nanobody containing periplasmic extracts. After washing and inactivation of endogenous phosphatases, bound phosphatase activity was measured using the CSPD substrate. Bars are the average \pm STDEV of triplicate measurements.

Figure 2 Specificity of nanobodies determined in a plate-binding assay

(A) Schematic representation of the extracellular architecture of the LR. CRH: cytokine receptor homology; Ig: immunoglobulin-like; FNIII: fibronectin type III. (B, C and D) Plates were coated with anti-HIS antibody, blocked, incubated with periplasmic extracts containing the nanobodies, and allowed to bind different SEAP fusion-proteins. Bound alkaline phosphatase activity was measured and plotted as the average of triplicate measurements. An example of an Ig-like, a $\mathrm{CRH} 2$, and a FNIII binder are shown in $\mathbf{B}, \mathbf{C}$, and $\mathbf{D}$ respectively.

Figure 3 Ig-like residues $\mathrm{H} 417$ and $\mathrm{H} 418$ are part of the epitope of some nanobodies Soluble $\mathrm{mLR}_{\mathrm{EC}}$ and mutants thereof were expressed in Hek293T cells. Expression was controlled with Western blot $(\mathbf{A})$ or by measurement of alkaline phosphatase activity in the supernatant (B). c Supernatant was applied in a platebinding assay as described in figure 2. Data are plotted as the percentage of wild type binding.

Figure 4 Targeting the $\mathrm{CRH} 2$, Ig-like and FNIII domains can result in inhibition of STAT3 signalling in mLR expressing cells

(A) Schematic representation of the structure of the bispecific nanobodies. mAlb: mouse serum albumin specific nanobody; GGS: flexible Gly-Gly-Ser linker. (B) mLR expressing Hek293T cells were stimulated overnight with $20 \mathrm{ng} / \mathrm{ml}$ leptin in the presence of a serial dilution of the $\mathrm{CRH} 2$ (2.17-mAlb), Ig-like (4.10-mAlb), and FNIII specific nanobody (4.11-mAlb). Luciferase activity was measured. Data are the mean of triplicate measurements, and results are representative of four independent experiments. (C) $L R$ transfected cells were stimulated with $100 \mathrm{ng} / \mathrm{ml}$ leptin in the presence of $50 ; 5 ; 0,5 ;$ and $0,05 \mu \mathrm{g} / \mathrm{ml}$ or no nanobodies for 5 (JAK2 phosphorylation) or 15 minutes (STAT3 phosphorylation). Lysates were prepared, blotted and JAK2-P, JAK2, STAT3-P, and STAT3 were revealed using specific nanobodies.

Figure 5 Binding Characteristics of purified Nanobodies

(A) Nanobody 2.17, but not 4.10 and 4.11 inhibit binding of leptin to its receptor. $\mathrm{mLR}$ transfected cells were incubated in medium containing leptin-SEAP and the indicated amounts of 2.17-mAlb, 4.10-mAlb, 4.11-mAlb, or leptin as a positive control. Bound enzymatic activity was measured as described in Figure 1. Bars are 
the average \pm STDEV of triplicate measurements. (B) Nanobodies 2.17, 4.10, and 4.11 bind the receptor with low nanomolar affinity. Plates coated with different bispecific nanobodies were allowed to bind a serial dilution $m L R_{E C}-S E A P$ (as indicated) for two hours. After four successive washes, bound enzymatic activity was measured. Data points represent average \pm STDEV of triplicate measurements. Data were fitted to a hyperbola (corresponding to a one site binding curve) using GraphPad Prism; curves shown are results of these fits. $R^{2}$ values are also included.

Figure 6 In vivo administration of mLR-specific nanobodies results in weight gain

(A) Body weight changes of C57BL/6 mice injected daily with bispecific nanobodies (4.10: 100, 40 and $10 \mu \mathrm{g} /$ day/mouse; 2.17: $100 \mu \mathrm{g} /$ day/mouse; 4.11: 100 $\mu \mathrm{g} / \mathrm{day} / \mathrm{mouse}$; for each $n=10)$, or PBS $(n=10)$ were followed for 7 days. Data are expressed as average \pm SEM (standard error of the mean). Results are representative for five different experiments. *, $P<0.05$; Mann-Whitney $U$ Test. (B) Mice were treated daily with 2.17-mAlb, 4.10-mAlb, or 4.11-mAlb (100 $\mu \mathrm{g} /$ day/mouse) for one week. At day seven, blood was collected, serum prepared and nanobody concentrations measured and plotted as average \pm SEM.

Figure 7 4.10-mAlb blocks leptin mediated downregulation of NPY expression in N38 cells and in the hypothalami of treated mice

(A) Serum-starved N38 cells were stimulated with $500 \mathrm{ng} / \mathrm{ml}$ leptin in the presence of indicated concentrations $4.10-\mathrm{mAlb}$ for 4 hours or were left unstimulated. (B) Mice were treated for one week with 4.10-mAlb (100 $\mu \mathrm{g} / \mathrm{mouse} / \mathrm{day})$ or PBS. After two additional injections of pegylated leptin (50 $\mu \mathrm{g} / \mathrm{mouse} / \mathrm{day})$, mice were sacrificed and hypothalami dissected. Quantitative RT- PCR analyses representing the NPY mRNA levels relative to these of PGK1 are plotted \pm STDEV. Results are representative for two independent experiments.

Figure 8 leptin:LR model with indication of nanobody target sites

Two LRs are shown in light gray and white, 2 leptin molecules in black. Two conserved cysteine residues in the FNIII domains are represented by spheres. Binding site I,II and III of leptin are indicated. For clarity of the figure, only a 2:2 leptin:LR complex is shown. In a hexameric 2:4 complex the binding sites I of both leptin molecules contact a third and fourth LR chain (not shown). 
Figure 1

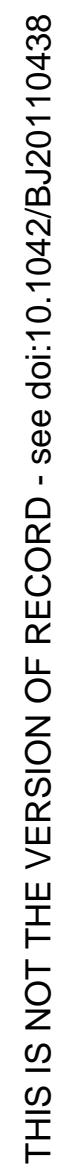

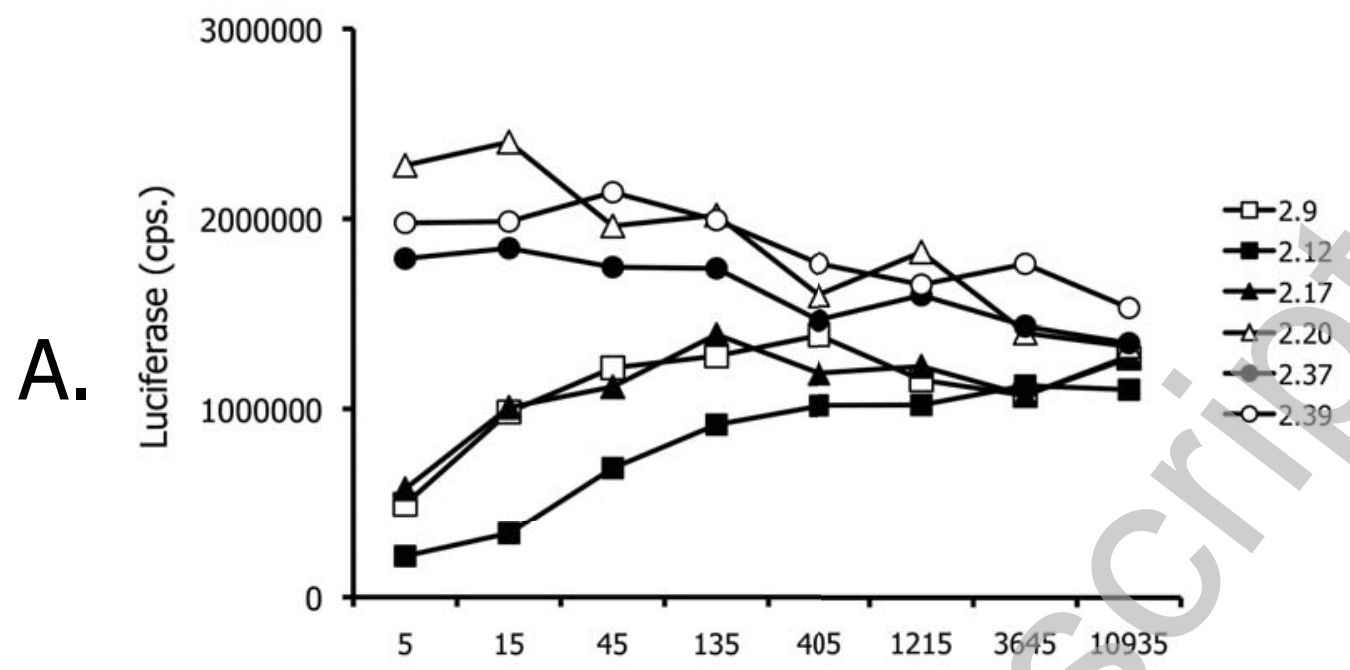

Dilution VHH periplasma

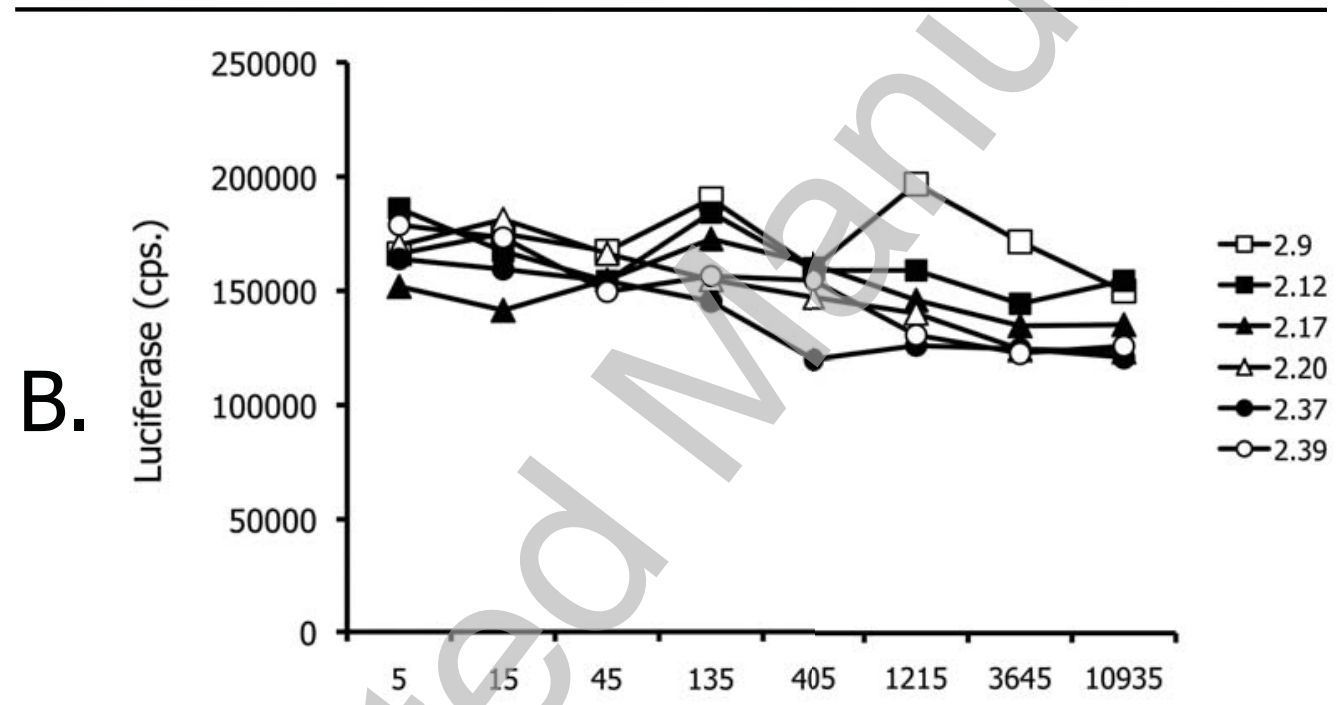

Dilution VHH periplasma

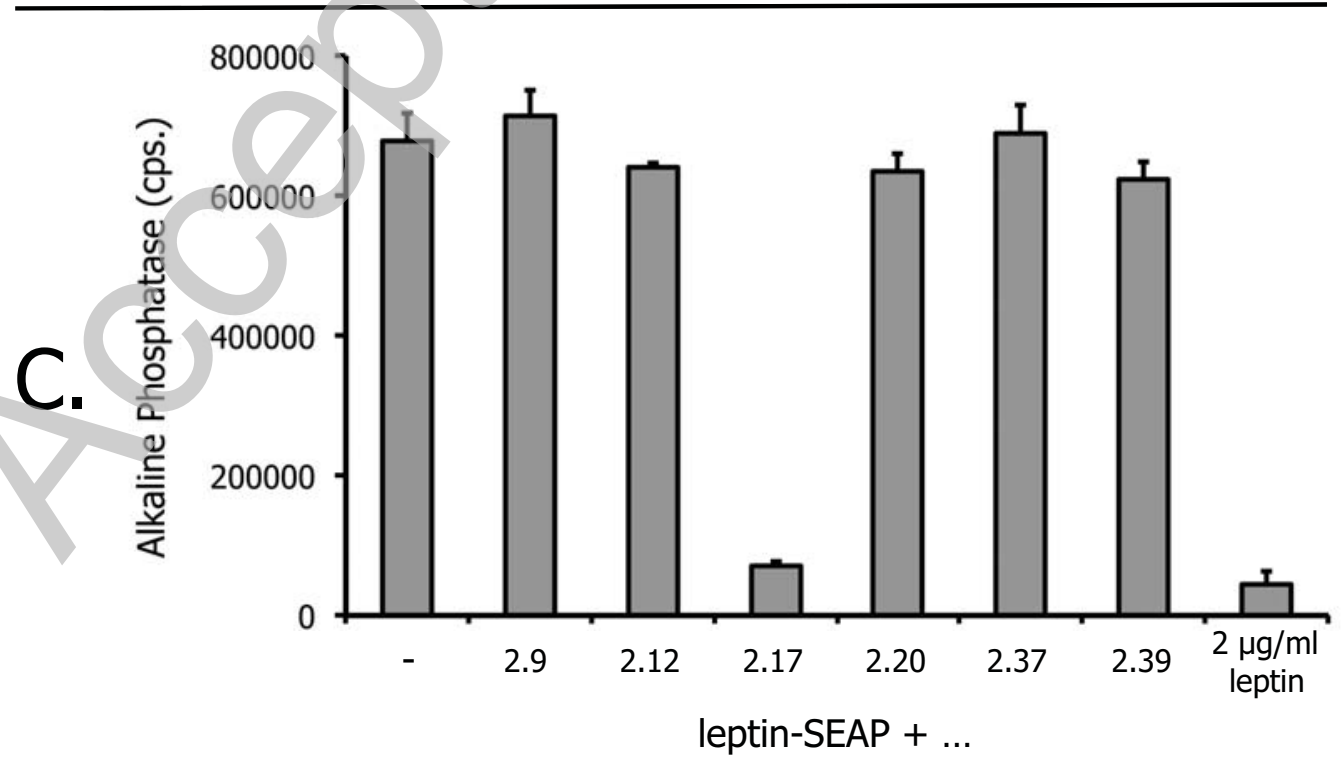

Licenced copy. Copying is not permitted, except with prior permission and as allowed by law.

(C) 2011 The Authors Journal compilation (c 2011 Portland Press Limited 
Figure 2

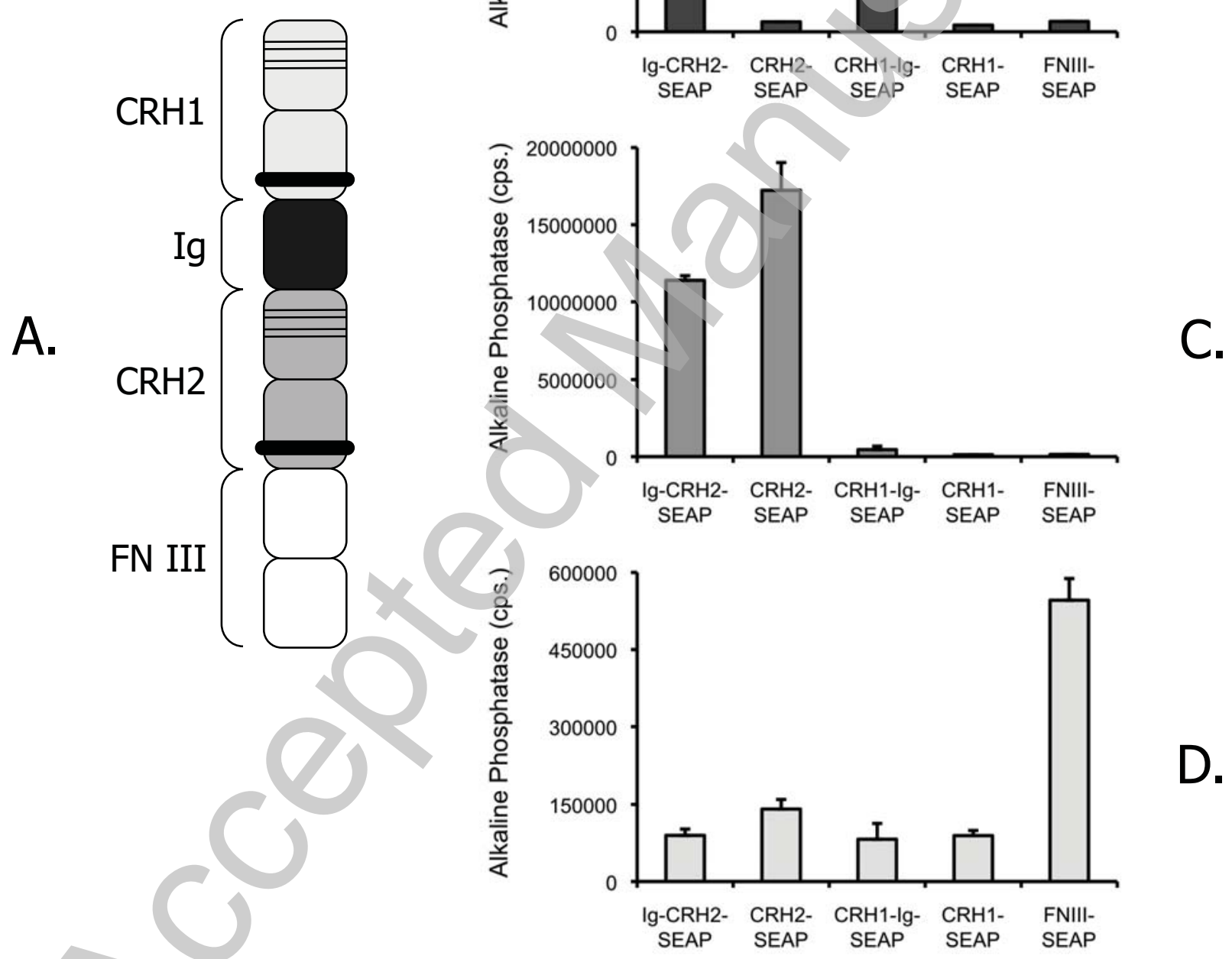


Figure 3
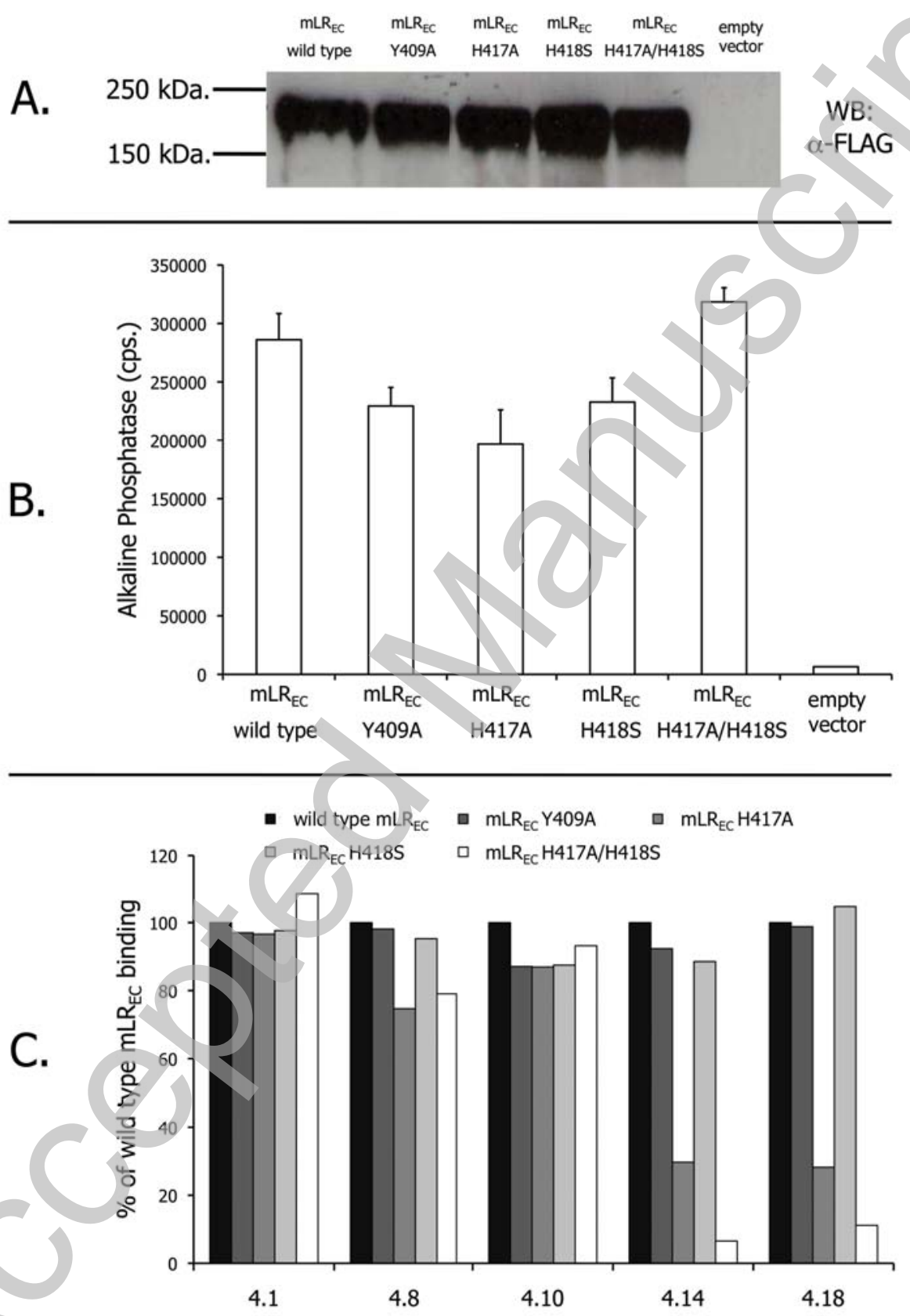
Figure 4
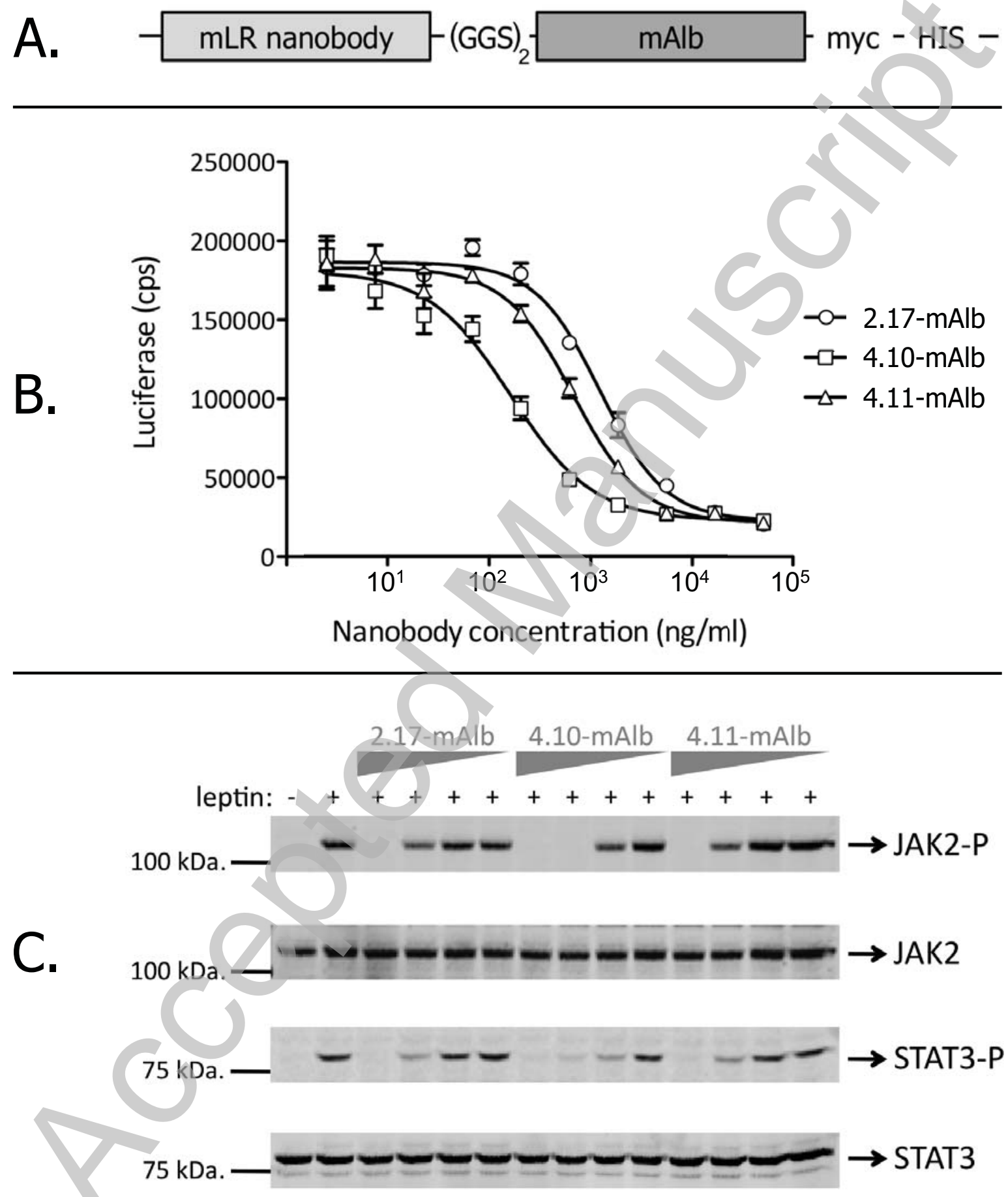
Figure 5

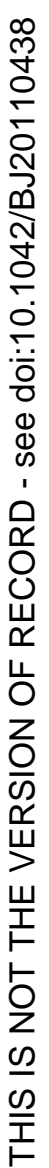
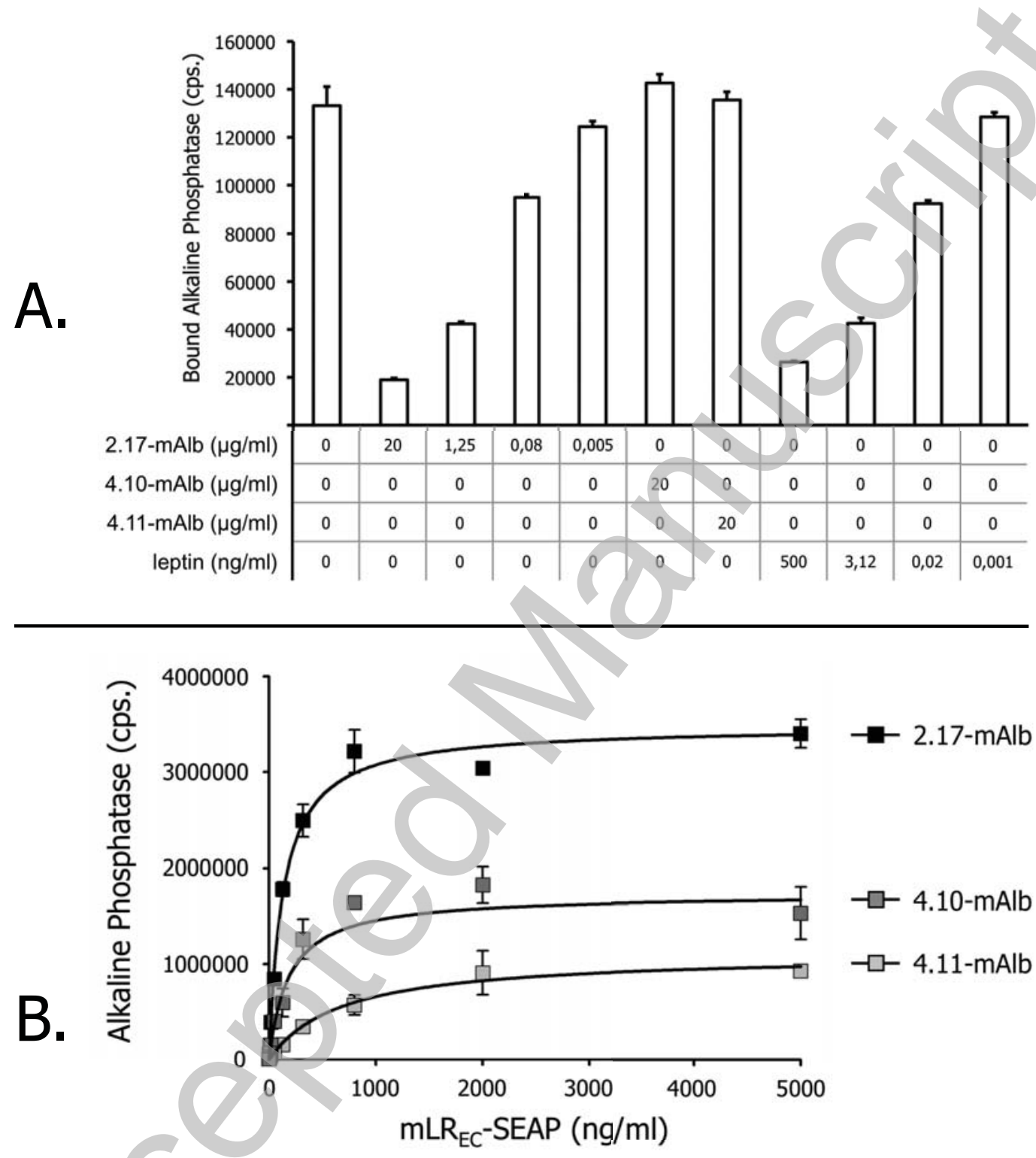

\begin{tabular}{c|c|c|c|}
\cline { 2 - 4 } & $\mathrm{K}_{\mathrm{D}}(\mathrm{nM})$ & $95 \%$ confidence interval & $\mathrm{R}^{2}$ \\
\hline $2.17-\mathrm{mAlb}$ & 0,472 & $0,299-0,646$ & 0,96 \\
$4.10-\mathrm{mAlb}$ & 2,668 & $1,732-3,605$ & 0,98 \\
$4.11-\mathrm{mAlb}$ & 0,740 & $0,322-1,158$ & 0,94
\end{tabular}

Licenced copy. Copying is not permitted, except with prior permission and as allowed by law. 
Figure 6
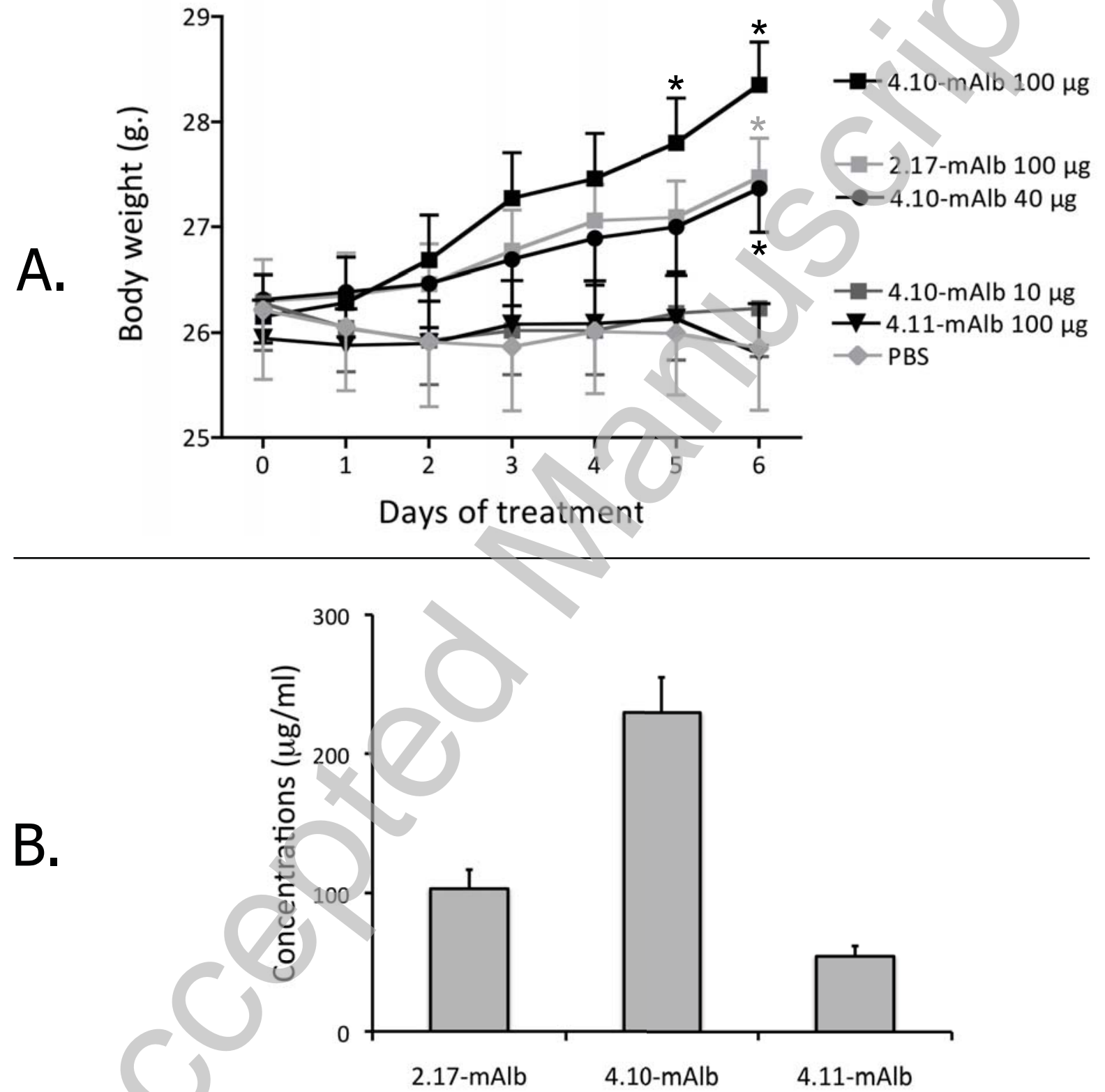
Figure 7

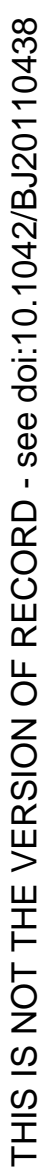
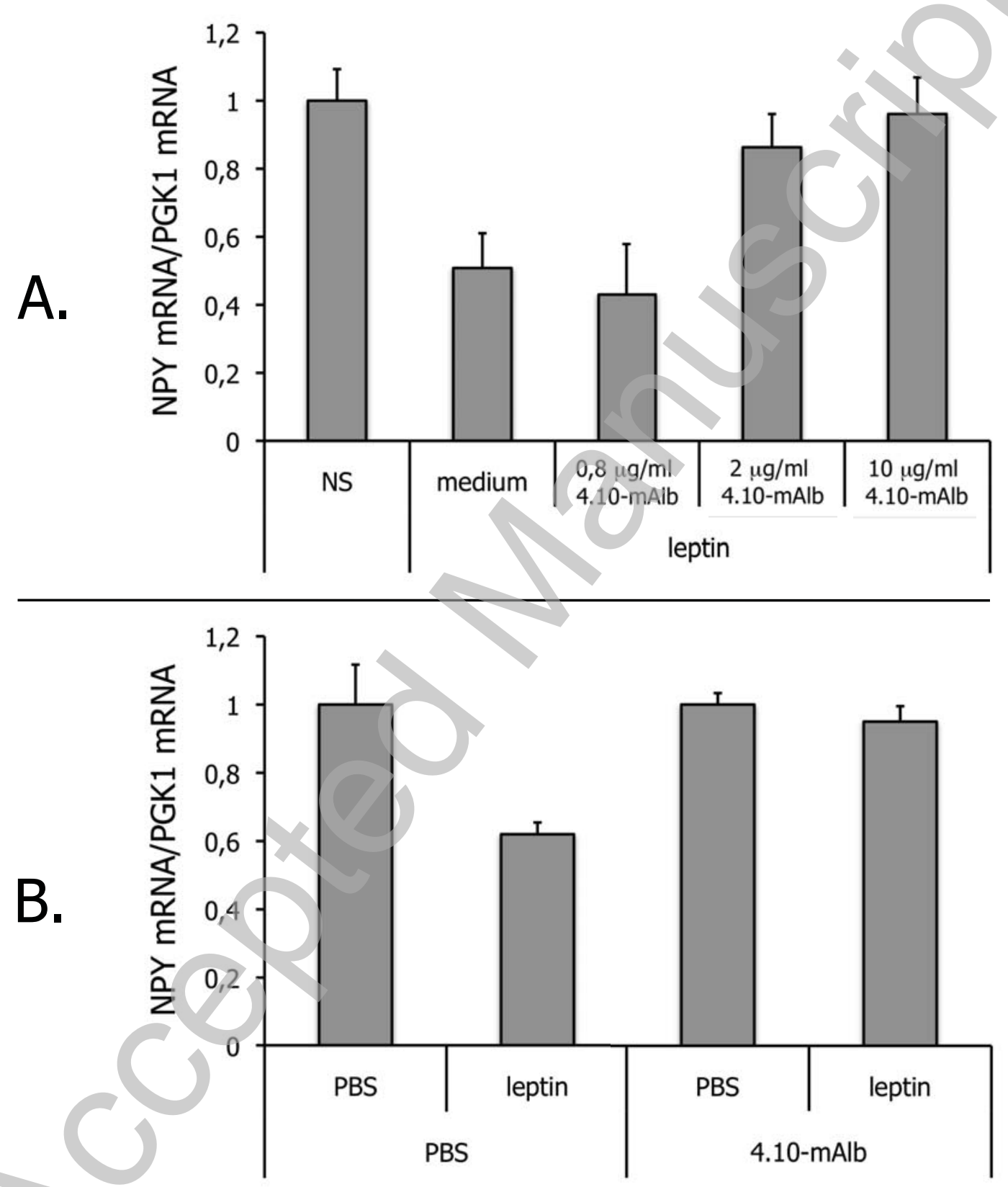
Figure 8

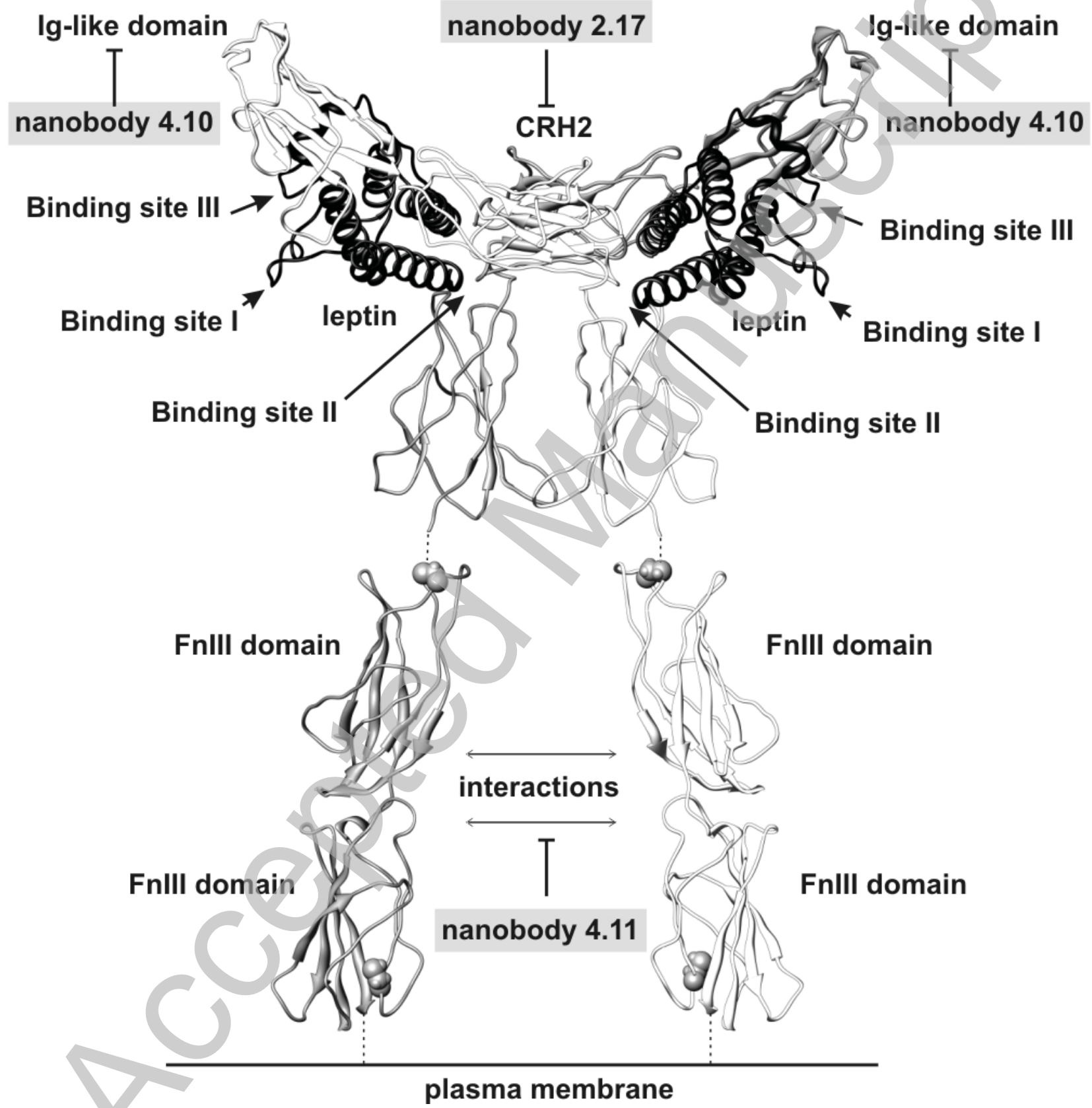

